
\title{
ZS Research Square \\ The Impact of Venture Capital Expenditures on Innovation in Europe
}

Angelo Leogrande ( $\sim$ leogrande.cultore@lum.it)

LUM UNIVERSITY

\section{ALBERTO COSTANTIELLO}

LUM UNIVERSITY

\section{LUCIO LAURETI}

LUM UNIVERSITY

\section{Research Article}

Keywords: Innovation and Invention: Processes and Incentives, Management of Technological Innovation and R\&D, Technological Change: Choices and Consequences, Intellectual Property and Intellectual Capital, Open Innovation, Government Policy

Posted Date: September 28th, 2021

DOI: https://doi.org/10.21203/rs.3.rs-936328/v1

License: (1) (1) This work is licensed under a Creative Commons Attribution 4.0 International License. Read Full License 


\title{
Angelo Leogrande ${ }^{1}$, Alberto Costantiello ${ }^{2}$, Lucio Laureti ${ }^{3}$ \\ The Impact of Venture Capital Expenditures on Innovation in Europe
}

\begin{abstract}
We investigate the relationship between "Venture Capital Expenditures" and innovation in Europe. Data are collected from the European Innovation Scoreboard for 36 countries in the period 20102019. We perform Panel Data with Fixed Effects, Panel Data with Random Effects, Pooled OLS, WLS, Dynamic Panel. Results show that the level of Venture Capitalist Expenditure is positively associated to "Foreign Doctorate Students" and "Innovation Index" and negatively related to "Government Procurement of Advanced Technology Products", "Innovators", "Medium and HighTech Products Exports", "Public-Private Co-Publications". In adjunct, cluster analysis is realized with the algorithm k-Means and the Silhouette coefficient, and we found the presence of four different clusters for the level of "Venture Capital Expenditures". Finally, we propose a confrontation among 8 different algorithms of machine learning to predict the level of "Venture Capital Expenditures" and we find that the linear regression generates the best results in terms of minimization of MAE, MSE, RMSE.
\end{abstract}

JEL CODE: O31, O32, O33, O34, O36, O38.

Keywords: Innovation and Invention: Processes and Incentives, Management of Technological Innovation and $R \& D$, Technological Change: Choices and Consequences, Intellectual Property and Intellectual Capital, Open Innovation, Government Policy.

\section{Introduction}

In this article we investigate the role of "Venture Capital Expenditure" in respect to innovation in European countries ${ }^{4}$ in the period 2010-2019. The role of innovation is essential to economic growth either in the short run either in the long run as showed in traditional economic theory [1], [2], [3]. The question of the financing of innovation is relevant since innovation is positively associated to human resources [4] [5], firms' sales [6], private investments [7], the presence of innovators [8], financefirm nexus [9]. Furthermore, innovation also requires a cultural and social environment pro-actively oriented toward technology and Research and Development [10]. Innovation has positive effects on employment [11]. The attractiveness of research systems at national level can improve innovation [12], [13]. The investment in innovation and Research and Development has positive effect on firm performance [14]. For these reasons it is necessary to analyze if the presence of venture capitalists can improve the level of innovation. Venture capitalists tend to invest in new technologies considering the financial returns. But there are sectors in which innovations are not sufficiently profitable such as for example in the case of cleantech [15]. In this case the investment of venture capitalists could be

\footnotetext{
${ }^{1}$ Assistant Professor of Economics at LUM University-Giuseppe Degennaro, Casamassima, Bari, Italy, EU.

${ }^{2}$ Professor of Economics and International Economics at LUM University-Giuseppe Degennaro, Casamassima, Bari, Italy, EU.

${ }^{3}$ Professor of Economics at LUM University-Giuseppe Degennaro, Casamassima, Bari, Italy, EU.

${ }^{4}$ Countries are Countries are Austria, Belgium, Bulgaria, Croatia, Cyprus, Czechia, Denmark, Estonia, Finlandia, France, Germany, Greece, Hungary, Iceland, Ireland, Israel, Italy, Latvia, Lithuania, Luxembourg, Malta, Montenegro, Netherlands, Norway, Poland, Portugal, Romania, Serbia, Slovakia, Slovenia, Spain, Switzerland, Turkey, Ukraine.
} 
inferior to the social optimal level and this situation can open a space for public intervention. But, in other cases, such as for example in the health sector, the investment of venture capitalists in innovation is either profitable either social relevant [16]. There is a positive relationship between public expenditure in Research and Development and venture capital especially in countries with low level of infrastructure [17]. More innovative economies that generate intellectual capital offer deeper investment opportunities for venture capitalists [18]. The investment of venture capital in Chinese start up has showed a controversial effect: at early-stage venture capitalists inhibit the investments of start ups in innovation while in the medium run the presence of external finance can promote a deeper technological innovation [19]. But, in the US, the investment of venture capitalists in start ups is positively associated to an increase in innovation and intellectual property rights [20]. Geographical locations have a role in creating the possibility of a connection between innovation and venture capital firms since both tend to distribute among urban districts [21]. Venture capitalists can promote the production of intellectual capital with greater efficiency in respect to traditional investment in Research and Development [22]. There is a positive relationship between venture capital and open innovation [23]. The role of venture capital is relevant in the case of countries that use startups to develop innovation systems [24]. Venture capitalists reduce the ability of young startups to develop deeper alliances tech-oriented [25]. If venture capital enterprises have a human capital with hard skills in STEM, then there are greater probabilities of a positive effect on the innovation abilities of the invested firms [26]. Venture capital invested firms improve their ability to innovate of $23 \%$ in Sweden [27]. Venture capitalists generate higher returns from innovation [28]. Venture capital can have a positive role to promote innovative start up especially in connection with high social capital and low taxation [29]. The relationship between startups and venture capital is more efficient when both share a common entrepreneurial culture that can work either as a scenario either as a model for commercial practices such as in the case of creative destruction in Silicon Valley [30]. Venture capital enterprises lack the ability to implement innovation in the long run with the industrialization of new products and services especially in comparison with start ups that receive public founding [31]. Venture capitalist enterprises promote deeper business innovation especially in the case of weak intellectual property rights regimes [32]. Researchers and entrepreneurs in innovation technology should consider the strategic role of venture capitalist firms in providing financial resources even considering the shortermism associated to a more profit-oriented management of intellectual assets in a knowledge economy [33]. Venture capital private enterprises are more efficient in respect to state-owned venture capital organizations in promoting innovation in China [34]. But the positive relationship between innovation and venture capital also shows the characteristics of non-linearity [35]. The development of an institutional framework for venture capital enterprises is positively associated to the digitalization of the entire economy [36].

The article continues as follows: the second paragraph presents the econometric model, the third paragraph contains the clusterization with k-Means algorithm, the fourth paragraph show a comparison among eight different algorithms of machine learning to predict the value of "Venture Capital Expenditures", the fifth paragraph concludes. The appendix contains further materials on regressions, clusterization, machine learning and prediction.

\section{The econometric model}

We have estimated the sequent model:

VentureCapitalExpenditures ${ }_{\text {it }}$

$=a_{1}+b_{1}(\text { ForeignDoctorateStudents })_{i t}$

$+b_{2}$ (GovernmentProcurementOf AdvacedTechnologyProducts) $)_{i t}$

$+b_{3}$ (InnovationIndex $)_{i t}+b_{4}(\text { Innovators })_{i t}$

$+b_{5}$ (MediumAndHighTechProductExports $)_{i t}$

$+b_{6}(\text { PublicPrivateCoPublications })_{i t}$ 
The level of "Venture Capital Expenditures" is defined as "[...] private equity being raised for investment in companies. Management buyouts, management buy-ins, and venture purchase of quoted shares are excluded. Venture capital includes early-stage (seed + start-up) and expansion and replacement capital. [11]» The variable is a proxy of the ability of a country to finance risks through capital accumulation either in traditional asset management either in innovative firms such as start ups and newcos. We estimate the value of "Venture Capital Expenditures" with the following econometric models i.e.: Panel Data with Random Effects, Panel Data with Fixed Effects, WLS, Pooled OLS, Dynamic Panel. Data are collected for 36 European countries in the period 2010-2019 from the European Innovation Scoreboard promoted by the European Commission. Results show that the level of "Venture Capital Expenditures" is positively associated to:

- "Foreign Doctorate Students": is defined as the percentage of foreign doctorate students as a percentage of all doctorate students. Is a measure of student international mobility. The variable has also a role in capturing the diffusion and dissemination of knowledge. Countries that are interested in improving the quality and quantity of human resources in Research and Development can augment the level of "Foreign Doctorate Students". There is a positive relationship between "Foreign Doctorate Students" and the level of "Venture Capital Expenditures". The positive relationship can be understood considering that generally the countries with more developed venture capital markets also have deeper international relationships and these relationships can also improve the presence of foreign students. In this case both the variables can be associated to a positive presence of the country in the international scenario.

- "Innovation Index": is a variable that describe the global ability of a country to innovate. There is a positive relationship between "Innovation Index" and "Venture Capital Expenditures". This positive relationship let us infer that the level of "Venture Capital Expenditures" captures an essential financial element of innovational capability of a country i.e., the ability to generate financial institutions, financial organizations and financial markets that can sustain risks either in innovation technology, start ups and newcos. A country that is interested in performing better in terms of innovation should promote reforms able to strengthen the role of venture capital markets and organizations.

\begin{tabular}{|c|c|l|c|}
\hline \multicolumn{5}{|c|}{ Variables in the Model with Label, Definitions and Main Relations } \\
\hline Label & Variables & \multicolumn{1}{|c|}{ Definitions } & Relations \\
\hline A59 & $y$ & Venture Capital Expenditures & \\
\hline A19 & $x_{1}$ & Foreign Doctorate Students & Positive \\
\hline A22 & $x_{2}$ & Government Procurement of Advanced Technology Products & Negative \\
\hline A24 & $x_{3}$ & Innovation Index & Positive \\
\hline A28 & $x_{4}$ & Innovators & Negative \\
\hline A35 & $x_{5}$ & Medium and High-Tech Product Exports & Negative \\
\hline A45 & $x_{6}$ & Public-Private Co-Publications & Negative \\
\hline
\end{tabular}

We also found that the level of "Venture Capital Expenditures" is negatively associated to:

- "Government Procurement of Advanced Technology Products": is a measure of the ability of a government to foster the supply of innovation technology through procurement and public demand. The variable is measured in a range between 1 and 7 in which in the case of 1 the choice of public procurement is based on price-based considerations while in the case of 7 the 
State choice based on the qualitative characteristics of the innovation technology produced. There is a negative relationship between "Venture Capital Expenditures" and "Government Procurement of Advanced Technology Products". This negative relationship shows the presence of a negative trade-off between the State-centered financing of innovation technology and the "Venture Capital Expenditures" methodologies that are more oriented to financial markets and the private sectors.

- "Innovators": is a complex variable that measure the ability of SMEs to innovate. Specifically, the variable "Innovators" is based on three different sub-variables that are "SMES with Product or Process Innovations", "SMEs with Marketing or Organisational Innovations", "SMEs Innovating In-House". There is a negative relationship between "Innovators" and "Venture Capital Expenditures". The negative relationship can be explained because in many European Countries the role of Venture Capital Market is under-developed i.e., in Southern and Eastern Europe.

- "Medium and High-Tech Product Exports": is a measure of the ability of a country to export products and services that are generated because of Research and Development expenditure and investments in innovation technology. Countries that are successful in implementing political economies oriented to innovation tend to have higher levels of "Medium and HighTech Product Exports". There is a positive relationship between the increasing degree of "Medium and High-Tech Product Exports" and the economic growth in connection to productivity and high levels of human resources. There is a negative relationship between "Medium and High-Tech Product Exports" and "Venture Capital Expenditures". The negative relationship ca be better understood considering that many European countries that have well developed market for innovation technology and products based on Research and Development, also are characterized by financial systems that are more oriented to banks rather than venture capital markets. The preference for banking systems in respect to financial systems have a role in reducing the ability to develop an efficient institutional environment for venture capital in association with high levels of innovation technology.

- "Public-Private Co-Publications": is a measure of the ability of collaboration between the private and the public sector captured as academic publications. Generally, the presence of a positive and collaborative linkages between the public and the private sector in Research and Development can be considered positively as a signal of the efficiency of the innovation system. Our results show the presence of a negative relationship between the presence of "Public-Private Co-Publications" and the level of "Venture Capital Expenditures". Also this relationship can seem counterfactual for the fact that an efficient innovation system based on a collaboration between the public and the private sector should also be associated to a greater presence of venture capital organizations. But, as we discussed before, many European countries that have higher scores in terms of innovation systems do lack to develop financial institutions able to promote venture capitalism.

\begin{tabular}{|c|c|c|c|c|c|c|c|c|c|c|c|c|c|c|c|c|}
\hline \multicolumn{17}{|c|}{ Stynthesis of the Main Results of the Econometric Model to Estimate the Value of Venture Capital Expenditures. Source: EIS. } \\
\hline & \multicolumn{3}{|c|}{ Random Effects } & \multicolumn{3}{|c|}{ Fixed Effects } & \multicolumn{3}{|c|}{ WLS } & \multicolumn{3}{|c|}{ Pooled OLS } & \multicolumn{3}{|c|}{ Dynamic Panel } & \multirow[b]{2}{*}{ Mean } \\
\hline & Coefficient & P-Valu & & Coefficient & P-Valu & & Coefficient & P-Val & & Coefficient & P-Val & & Coefficient & P-Valt & & \\
\hline const & $-1,62699$ & 0,8011 & & $-1,71181$ & 0,679 & & $-2,83458$ & 0,3913 & & $-1,21441$ & 0,7984 & & 8,86477 & 0,0926 & * & \\
\hline$A 19$ & 0,440021 & $<0,0001$ & $* * *$ & 0,434459 & $<0,0001$ & $* * *$ & 0,442011 & $<0,0001$ & $* * *$ & 0,448861 & $<0,0001$ & $* * *$ & 0,360208 & 0,0009 & $* * *$ & 0,42511 \\
\hline$A 22$ & $-1,92811$ & $<0,0001$ & **** & $-1,91873$ & $<0,0001$ & $* * *$ & $-1,50959$ & $<0,0001$ & $* * *$ & $-1,92372$ & $<0,0001$ & $* * *$ & $-2,1116$ & $<0,0001$ & $* * *$ & $-1,8784$ \\
\hline$A 24$ & 1,61066 & $<0,0001$ & $* * *$ & 1,64568 & $<0,0001$ & $* * *$ & 1,2422 & $<0,0001$ & $* * *$ & 1,54652 & $<0,0001$ & $* * *$ & 1,42184 & $<0,0001$ & $* * *$ & 1,49338 \\
\hline$A 28$ & $-0,471011$ & $<0,0001$ & $* * *$ & $-0,487285$ & $<0,0001$ & **** & $-0,328202$ & $<0,0001$ & $* * *$ & $-0,441353$ & $<0,0001$ & $* * *$ & $-0,325622$ & 0,0002 & $* * *$ & $-0,4107$ \\
\hline A35 & $-0,287397$ & 0,0029 & $* * *$ & $-0,299902$ & 0,0091 & $* * *$ & $-0,150725$ & 0,0013 & $* * *$ & $-0,268766$ & 0,0002 & $* * *$ & $-0,517182$ & 0,0432 & $* *$ & $-0,3048$ \\
\hline$A 45$ & $-0,400998$ & $<0,0001$ & $* * *$ & $-0,404364$ & $<0,0001$ & **** & $-0,346997$ & $<0,0001$ & $* * *$ & $-0,394264$ & $<0,0001$ & $* * *$ & $-0,295887$ & 0,0173 & $* *$ & $-0,3685$ \\
\hline$A 59(-1)$ & & & & & & & & & & & & & $-0,248649$ & 0,0028 & **** & \\
\hline
\end{tabular}

Figure 1. Synthesis of the Main Results of the Econometric Model to Estimate the Value of Venture Capital Expenditures. Source: EIS. 
We can also consider the mean value of the single variables to create an order of variables in the sense of impact. Our results show that "Innovation Index" has the main positive impact on "Venture Capital Expenditures" with a mean value of 1,49. "Government Procurement of Advanced Technology Products" has the most relevant negative impact of "Venture Capital Expenditure" with a mean value equal to $-1,87$.

\begin{tabular}{|c|c|c|c|c|}
\hline \multicolumn{5}{|c|}{$\begin{array}{l}\text { Ranking of the Mean Value of the Results of Five Models Used to Estimate the Value of } \\
\text { Venture Capital Expenditures. }\end{array}$} \\
\hline Rank & & Variable & Mean & Impact \\
\hline 1 & $A 24$ & Innovation Index & 1,4934 & \multirow{2}{*}{ Positive Effects } \\
\hline 2 & $A 19$ & Foreign Doctorate Students & 0,4251 & \\
\hline 3 & $A 35$ & Medium and High-Tech Product Exports & $-0,3048$ & \multirow{4}{*}{ Negative Effects } \\
\hline 4 & $A 45$ & Public-Private Co-Publications & $-0,3685$ & \\
\hline 5 & $A 28$ & Innovators & $-0,4107$ & \\
\hline 6 & $A 22$ & Government Procurement of Advanced Technology Products & $-1,8784$ & \\
\hline
\end{tabular}

Figure 2. Ranking of the Mean Value of the Results of Five Models Used to Estimate the Value of Venture Capital Expenditures.

Finally, we can observe that the value of "Venture Capital Expenditure" is not clearly and positively associated to many determinants of innovation. The negative relationships among "Venture Capital Expenditure" and other variables, should not be considered as a manifestation of a theoretical model, but as a particular case for European countries. Since European countries are, in large part, based on banking systems, they also suffer more for the lack of external finance and venture capitalism. If policy makers, are interested in promoting "Venture Capital Expenditures", then they also should consider to reform financial institutions and organizations and opening markets to venture capital organizations and enterprises.

\section{Clusterization}

In adjunct we perform a cluster analysis with the algorithm k-Means optimized with the Silhouette coefficient. We find four different clusters i.e.:

- Cluster 1: Ukraine, Slovakia, Czechia, Greece, Slovenia, Serbia, Poland, Bulgaria, Croatia, Romania, Austria;

- Cluster 2: Spain, Sweden, Finland, Norway, Belgium, Estonia, Portugal, Ireland, Denmark, Germany, Hungary, Netherlands, Lithuania, Cyprus, Switzerland, Italy;

- Cluster 3: Malta, Latvia;

- Cluster 4: France, Luxembourg, United Kingdom. 


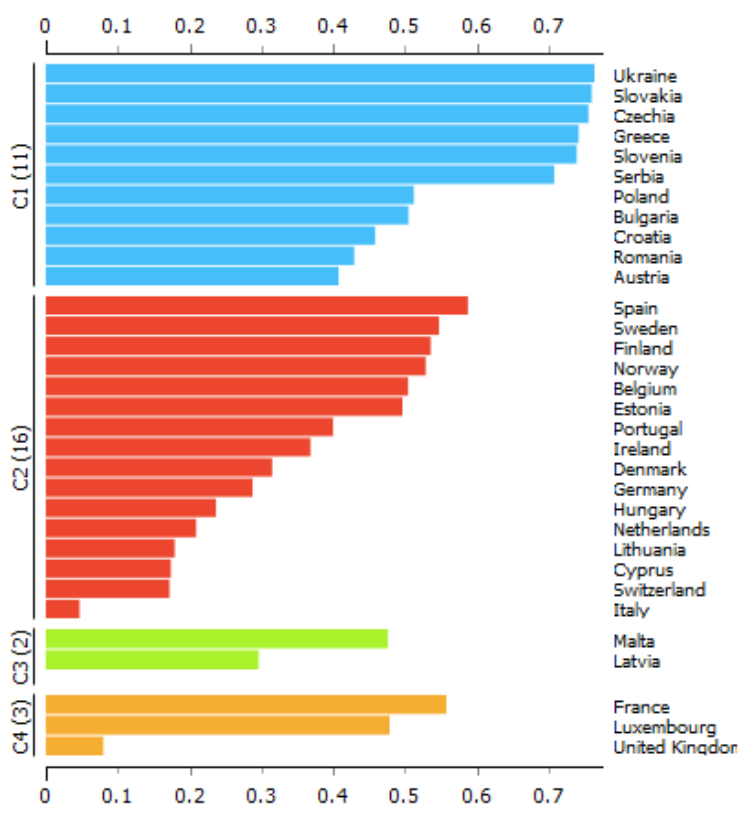

Figure 3. Synthesis of the main results of the cluster analysis with the algorithm k-Means optimized with the Silhouette Coefficient

We find that the four clusters perform in very different ways. Specifically, the fourth cluster-C4, has a mean value of "Venture Capital Expenditure" equal to 300,3 and it is at the highest rank among clusters. Cluster 2-C2 follows with a mean value of "Venture Capital Expenditures" equal to 193,7. Cluster 1 is at the third place with a level of the mean value of "Venture Capital Expenditures" equal to 50,89. Finally, Cluster 3-C3 has the lowest level of mean value of "Venture Capital Expenditures" with a mean value of 15,3. The order of cluster for mean value of "Venture Capital Expenditures" is $\mathrm{C} 4>\mathrm{C} 2>\mathrm{C} 1>\mathrm{C} 3$.

\begin{tabular}{|c|c|c|c|c|}
\hline \multicolumn{5}{|c|}{ Ranking of Clusters for Mean Value } \\
\hline Rank & Cluster & MIN & MAX & MEAN \\
\hline 1 & C4 & 292,8 & 304,1 & 300,3 \\
\hline 2 & $\mathrm{C2}$ & $\hat{w} 85,66$ & 304,1 & 193,7 \\
\hline 3 & C1 & 7,48 & 122 & $\star 50,89$ \\
\hline 4 & C3 & 7,87 & $+22,72$ & 15,3 \\
\hline
\end{tabular}

Figure 4. Ranking of clusters for Mean Value.

Finally, we can observe that there is a great gap among the four different clusters. Specifically, the second cluster-C2 has a mean value of "Venture Capital Expenditures" equal to 64,51\% of the correspondent value $\mathrm{C} 4$, while the same value of $\mathrm{C} 1$ is equal to $16,9 \%$ of the value of $\mathrm{C} 4$. In the end countries in the third cluster-C3 have a mean value of "Venture Capital Expenditures" equal to 5,09\% of the value of the correspondent value of the leading Cluster 4-C4. 


\section{Predictions}

We use eight different machine learning algorithms to predict the level of "Venture Capital Expenditures". We divide the dataset in two parts using the node in KNIME named "Partitioning": $70 \%$ of train and $30 \%$ of test. We compare the efficiency of the machine learning algorithms using three different measures of errors i.e.: Mean Squared Error-MSE, Mean Absolute Error-MAE and Root Mean Squared Error-RMSE.

\begin{tabular}{|c|c|c|c|c|c|c|c|c|}
\hline Rank & Algorithms & Mean Squared Error & Rank & Algorithms & Mean Absolute Error & Rank & Algorithms & Root Mean Squared Error \\
\hline & Linear Regression & 0,025606 & & Linear Regression & \begin{tabular}{|r}
0,110690 \\
\end{tabular} & & Linear Regression & 0,160018 \\
\hline 2 & ANN & 0,032685 & & $A N N$ & 0,120775 & & ANN & 0,180791 \\
\hline 3 & Tree Ensemble Regression & 0,047914 & & Random Forest Regression & 0,130767 & 3 & Tree Ensemble Regression & 0,218892 \\
\hline & Random Forest Regression & 0,049777 & & PNN & 0,167717 & 4 & Random Forest Regression & 0,223107 \\
\hline 5 & PNN & 0,053763 & & Tree Ensemble Regression & 0,198501 & & PNN & 0,231869 \\
\hline 6 & Polynomial Regression & 0,072156 & & Polynomial Regression & 0,205896 & & Polynomial Regression & 0,268619 \\
\hline & Simple Regression Tree & 0,116145 & & Simple Regression Tree & 0,221881 & & Simple Regression Tree & 0,340800 \\
\hline & Gradient Boosted Trees Regression & 0,138305 & & Gradient Boosted Trees Regression & 0,260648 & & Gradient Boosted Trees Regression & 0,371894 \\
\hline
\end{tabular}

We choose the best algorithm considering the minimization of errors. We use the following algorithms i.e.:

- Linear Regression;

- ANN-Artificial Neural Networks;

- Tree Ensemble Regression;

- Random Forest Regression;

- Probabilistic Neural Networks-PNN;

- Polynomial Regression;

- Simple Regression Tree;

- Gradient Boosted Tree Regression.

We find that the best algorithm to predict the level of "Venture Capital Expenditures" is "Linear Regression", followed in order by "Artificial Neural Network-ANN", "Tree Ensemble Regression", "Random Forest Regression", "Probabilistic Neural Network-PNN", "Polynomial Regression", "Simple Regression Tree", "Gradient Boosted Trees Regression".

\begin{tabular}{|c|c|c|c|c|c|}
\hline \multicolumn{6}{|c|}{ Ranking of Algorithm Based on the Minimization of MSE, MAE and RMSE } \\
\hline Rank Algorithm & Mean Squared Error & Mean Absolute Error & & Root Mean Squared Error & Total \\
\hline \begin{tabular}{l|l|}
1 & Linear Regression \\
\end{tabular} & t 1 & 1 t & 1 & t & 1 th 3 \\
\hline $2 \mid A N N$ & h & 2 th & 2 & th & 2 is 6 \\
\hline \begin{tabular}{l|l}
3 & Tree Ensemble Regression \\
\end{tabular} & th & 3 放 & & $t^{2}$ & $3 \rightarrow 11$ \\
\hline 3 Random Forest Regression & th & 4 在 & & 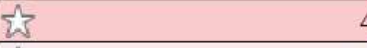 & 4 int 11 \\
\hline \begin{tabular}{l|l|l|}
4 & $P N N$ \\
\end{tabular} & है & 5 ל & & ts & 5 th 14 \\
\hline \begin{tabular}{l|l}
5 & Polynomial Regression \\
\end{tabular} & is & $6 \sqrt{5}$ & & $\hbar^{2}$ & \begin{tabular}{|l|l|}
6 & 18 \\
\end{tabular} \\
\hline 6 Simple Regression Tree & th & 7 约 & 7 & $\hat{2}$ & $7+21$ \\
\hline 7 Gradient Boosted Trees Regression & th & 8 约 & & ts & $8+24$ \\
\hline
\end{tabular}

Figure 5. Ranking of machine learning algorithms based on the minimization of MSE, MAE and RMSE. 


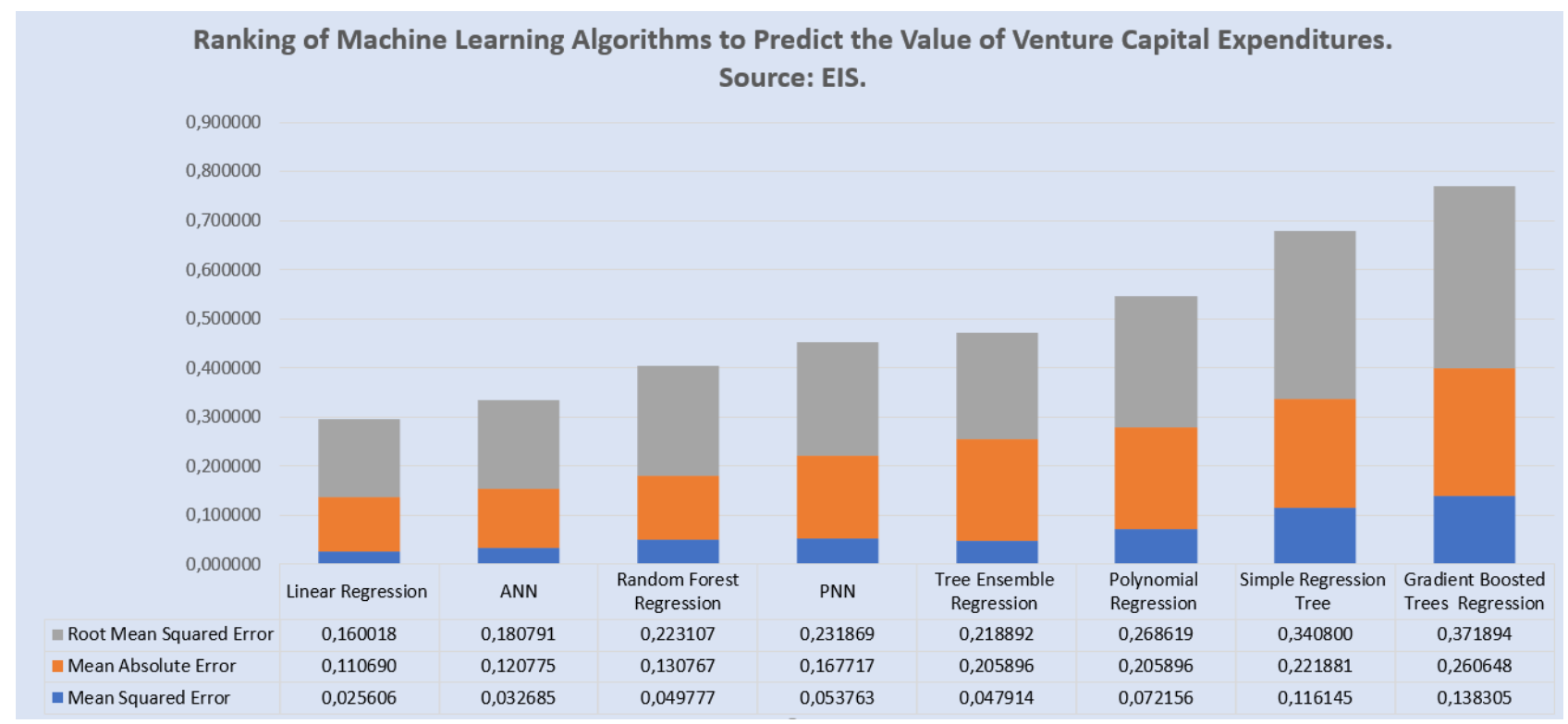

Figure 6. Ranking of machine learning algorithms to predict the value of "Venture Capital Expenditures".

\section{Conclusions}

We investigate the relationship between "Venture Capital Expenditures" and innovation in Europe. We collect data from the European Innovation Scoreboard for 36 countries in the period 2010-2019. In the first paragraph we have analyzed different articles from the scientific literature that positively associate "Venture Capital Expenditures" to innovation. But, in the following part, when we have realized the econometric analysis, we found some counterfactual results. In our econometric analysis we have applied different models: Panel Data with Fixed Effects, Panel Data with Random Effects, Pooled OLS, WLS, Dynamic Panel. Results show that the level of Venture Capitalist Expenditure is positively associated to "Foreign Doctorate Students" and "Innovation Index" and negatively related to "Government Procurement of Advanced Technology Products", "Innovators", "Medium and HighTech Products Exports", "Public-Private Co-Publications". Contrary to our expectations we found that the presence of "Venture Capital Expenditures" is not able to promote that deep impact on innovation that we have encountered in the literature. The gap between the theoretical framework and our results can be understood considering that in many European countries the markets for venture capital lack the necessary institutions and infrastructure. In adjunct, we must note that many European countries are banking-oriented instead of market oriented and tend to reduce the impact of external finance especially in the case of Central and Southern European countries. These facts can explain why we do not find a so deep connection between "Venture Capital Expenditures" and innovation in European countries. In the third paragraph we have realized a clusterization with k-Means algorithm optimized with Silhouette coefficient and we show the presence of four different clusters in Europe based on the level of "Venture Capital Expenditures". Finally, we propose a confrontation among 8 different algorithms of machine learning to predict the level of "Venture Capital Expenditures" and we find that the linear regression generates the best results in terms of minimization of MAE, MSE, RMSE. 


\section{Bibliography}

[1] R. M. Solow, "A Contribution to the Theory of Economic Growth," The Quarterly Journal of Economics, vol. 70, n. 1, pp. 65-94, 1956.

[2] P. M. Romer, «The Origins of Endogenous Growth,» Journal of Economic Perspectives, vol. 8, n. 1, pp. 3-22, 1994.

[3] J. Schumpeter, The Theory of Economic Development: an Inquiry into Profits, Capital, Credit, Interest, and the Business Cycle, New Brunswick: Transaction Books, 1934.

[4] A. Leogrande e A. Costantiello, «Human Resources in Europe. Estimation, Clusterization, Machine Learning and Prediction," American Journal of Humanities and Social Sciences Research (AJHSSR), vol. 5, n. 9, pp. 240-259, 2021.

[5] A. Leogrande, A. Massaro e A. M. Galiano, "The Determinants of Human Resources in European Countries During the Period 2010-2019," American Journal of Humanities and Social Sciences Research (AJHSSR), vol. 4, n. 9, pp. 145-171, 2020.

[6] A. Costantiello, L. Laureti e G. L. A. De Cristoforo, «The Innovation-Sales Growth Nexus in Europe,» University Library of Munich, 2021.

[7] A. Costantiello, L. Laureti e A. Leogrande, «The Determinants of Firm Investments in Research and Development," International Virtual Academic Conference Education and Social Sciences Business and Economics, 2021.

[8] A. Costantiello, L. Laureti e A. Leogrande, «The SMEs Innovation in Europe,» FEMIB, pp. 23-32, 2021.

[9] L. Laureti, A. Costantiello e A. Leogrande, «Finance-Innovation Nexus in Europe," JISET -International Journal of Innovative Science, Engineering \& Technology, vol. 7, n. 12, 2020 .

[10] A. Leogrande, A. Costantiello e A. Laureti, «The Innovation-Friendly Environment in Europe,» ICSETInternational Conference on Science, Engineering \& Technology (ICSET-2021), 2021.

[11] A. Costantiello e A. Leogrande, "The innovation-employment nexus in Europe," American Journal of Humanities and Social Sciences Research (AJHSSR), vol. 4, n. 11, pp. 166-187, 2020.

[12] A. Leogrande, A. Massaro e A. M. Galiano, "The Attractiveness of European Research Systems, " American Journal of Humanities and Social Sciences Research (AJHSSR) , vol. 4, n. 10, pp. 72-101, 2020.

[13] A. Leogrande, A. Massaro e A. M. Galiano, «The Determinants of Innovation in European Countries in the period 2010-2019," American Journal of Humanities and Social Sciences Research (AJHSSR), vol. 4, n. 8, pp. 91-126, 2020.

[14] A. Leogrande e A. G. A. M. Massaro, "The Impact of R\&D Investments on Corporate Performance in European Countries," American Journal of Humanities and Social Sciences Research (AJHSSR), vol. 4, n. 7, pp. 186-201, 2020. 
[15] B. E. Gaddy, V. Sivaram, T. B. Jones e L. Wayman, «Venture capital and cleantech: The wrong model for energy innovation,» Energy Policy, vol. 102, pp. 385-395, 2017.

[16] F. A. Frimpong, E. K. Akwaa-Sekyi e R. Saladrigues, «Venture capital healthcare investments and health care sector growth: A panel data analysis of Europe,» Borsa Istanbul Review, 2021.

[17] H. Herrera-Echeverry, «Public Expenditure in Research and Development and Venture Capital Commitments, » Engineering Economics, vol. 28, n. 3, pp. 240-252, 2017.

[18] Y. Lu, Z. Tian, G. A. Buitrago, S. Gao, Y. Zhao e S. Zhang, «Intellectual capital and firm performance in the context of venture-capital syndication background in China,» Complexity, 2021.

[19] H. Qiao, S. Zhang e Y. Xiao, «Modeling the Impacts of Venture Capital Investment on Firm Innovation,» Discrete Dynamics in Nature and Society, 2021.

[20] J. H. Park e Z. T. Bae, «When are 'sharks' beneficial? Corporate venture capital investment and startup innovation performance," Technology Analysis \& Strategic Management, vol. 30, n. 3, pp. 324-336, 2018.

[21] R. Florida e K. M. King, "Urban start-up districts: Mapping venture capital and start-up activity across ZIP codes, "Economic Development Quarterly, vol. 32, n. 2, pp. 99-118, 2018.

[22] M. Schnitzer e M. Watzinger, "Measuring the spillovers of venture capital,» The Review of Economics and Statistics, pp. 1-48, 2017.

[23] R. Yi, H. Wang, B. Lyu e Q. Xia, «Does venture capital help to promote open innovation practice? Evidence from China,» European Journal of Innovation Management, 2021.

[24] C. Norrby e S. Åslund, he Role of Venture Capital in Innovation Systems-A Case Study Comparing the Possible Risks and Rewards for Volvo Group Venture Capital Between Initiating Investments in China, India, Japan, Singapore, South Korea, and Taiwan, vol. Sweden, Gothenburg: Master's Thesis in Management and Economics of Innovation Chalmers Univerisity of Technology, 2021, p. Gothenburg.

[25] T. L. Galloway, D. R. Miller, A. Sahaym e J. D. Arthurs, «Exploring the innovation strategies of young firms: Corporate venture capital and venture capital impact on alliance innovation strategy,» Journal of Business Research, vol. 71, pp. 55-65, 2017.

[26] X. Jin, P. Zheng, Z. Zhong e Y. Cao, «The Effect of Venture Capital on Enterprise Benefit According to the Heterogeneity of Human Capital of Entrepreneur, " Frontiers in Psychology, vol. 11, p. 1558, 2020.

[27] E. Dahlberg e S. Sörling, The Money of Innovation: The Impact of Venture Capital on Innovation in Sweden, Uppsala : Uppsala University, 2019.

[28] J. González-Uribe, «Exchanges of innovation resources inside venture capital portfolios,» Journal of Financial Economics, vol. 135, n. 1, pp. 144-168, 2020.

[29] L. Grilli, B. Mrkajic e G. Latifi, «Venture capital in Europe: social capital, formal institutions and mediation effects,» Small Business Economics, vol. 5, n. 12, pp. 393-410, 2018.

[30] S. Hogarth, «Valley of the unicorns: consumer genomics, venture capital and digital disruption,» New Genetics and Society, vol. 36, n. 3, pp. 250-272, 2017. 
[31] M. Da Rin e M. F. Penas, " Venture capital and innovation strategies, " Industrial and Corporate Change, vol. 26, n. 5, pp. 781-800, 2017.

[32] A. Safari, «Venture capital and intellectual property rights effects on innovation in different socioeconomic environments: a systematic review and exploration of various contradictive studies, International Journal of Economics and Business Research, vol. 15, n. 3, pp. 373-397, 2018.

[33] M. Rossi e E. Martini, «Venture capitalists and value creation: The role of informal investors in the growth of smaller European firms, "International Journal of Globalisation and Small Business, vol. 10, n. 3, pp. 233-247, 2019 .

[34] W. Sun, Y. Zhao e L. Sun, «Big data analytics for venture capital application: towards innovation performance improvement, » International Journal of Information Management, vol. 50, pp. 557-565, 2020.

[35] J. Wen, D. Yang, G. F. Feng, M. Dong e C. P. Chang, "Venture capital and innovation in China: The nonlinear evidence," Structural Change and Economic Dynamics, vol. 46, pp. 148-162, 2018.

[36] R. P. Pradhan, M. B. Arvin, M. Nair, S. E. Bennett e S. Bahmani, "Short-term and long-term dynamics of venture capital and economic growth in a digital economy: A study of European countries, » Technology in Society, vol. 57, pp. 125-134, 2019.

[37] H. Hollanders, N. Es-Sadki, D. Vértesy e G. Damioli, «European Innovation Scoreboard 2017Methodology Report,» European Commission, Bruxelles , 2017.

\section{Appendix}

\subsection{Regression Analysis}

\begin{tabular}{|c|c|c|c|c|c|}
\hline \multicolumn{6}{|c|}{ Effetti casuali (GLS), usando 360 osservazioni } \\
\hline \multicolumn{6}{|c|}{ Incluse 36 unità cross section } \\
\hline \multicolumn{6}{|c|}{ Lunghezza serie storiche $=10$} \\
\hline \multicolumn{6}{|c|}{ Variabile dipendente: A59 } \\
\hline \multicolumn{2}{|r|}{ Coefficiente } & Errore Std. & $z$ & \multicolumn{2}{|l|}{ p-value } \\
\hline const & $-1,62699$ & 6,45866 & $-0,2519$ & \multicolumn{2}{|l|}{0,8011} \\
\hline A19 & 0,440021 & 0,0499974 & 8,801 & $<0,0001$ & $* * *$ \\
\hline A22 & $-1,92811$ & 0,297818 & $-6,474$ & $<0,0001$ & $* * *$ \\
\hline A24 & 1,61066 & 0,187872 & 8,573 & $<0,0001$ & $* * *$ \\
\hline A28 & $-0,471011$ & 0,102440 & $-4,598$ & $<0,0001$ & $* * *$ \\
\hline A35 & $-0,287397$ & 0,0965637 & $-2,976$ & 0,0029 & $* * *$ \\
\hline A45 & $-0,400998$ & 0,0590096 & $-6,795$ & $<0,0001$ & $* * *$ \\
\hline \multicolumn{2}{|l|}{ Media var. dipendente } & 3460 & SQM var. dipendente & \multicolumn{2}{|c|}{75,57819} \\
\hline Somma quadr. residui & \multicolumn{2}{|c|}{731499,4} & E.S. della regressione & \multicolumn{2}{|c|}{45,45748} \\
\hline Log-verosimiglianza & \multicolumn{2}{|c|}{$-1881,832$} & Criterio di Akaike & \multicolumn{2}{|c|}{3777,665} \\
\hline
\end{tabular}




\begin{tabular}{llll}
\hline Criterio di Schwarz & 3804,868 & Hannan-Quinn & 3788,481 \\
\hline rho & 0,636696 & Durbin-Watson & 0,698379 \\
\hline
\end{tabular}

\begin{tabular}{|l|}
\hline \multicolumn{1}{|c|}{$0,636696 \quad$ Durbin-Watson } \\
\hline \\
\hline Varianza 'between' $=925,392$ \\
\hline Varianza 'within' $=1324$ \\
\hline Theta usato per la trasformazione $=0,646211$ \\
\hline Test congiunto sui regressori - \\
\hline Statistica test asintotica: Chi-quadro(6) $=558,115$ \\
\hline con p-value $=2,51333$ - 117 \\
\hline \\
\hline Test Breusch-Pagan - \\
\hline Ipotesi nulla: varianza dell'errore specifico all'unità $=0$ \\
\hline Statistica test asintotica: Chi-quadro(1) = 206,224 \\
\hline con p-value $=9,15688$-047 \\
\hline \\
\hline Test di Hausman - \\
\hline Ipotesi nulla: le stime GLS sono consistenti \\
\hline Statistica test asintotica: Chi-quadro(6) $=0,499397$ \\
\hline con p-value = 0,997846 \\
\hline
\end{tabular}




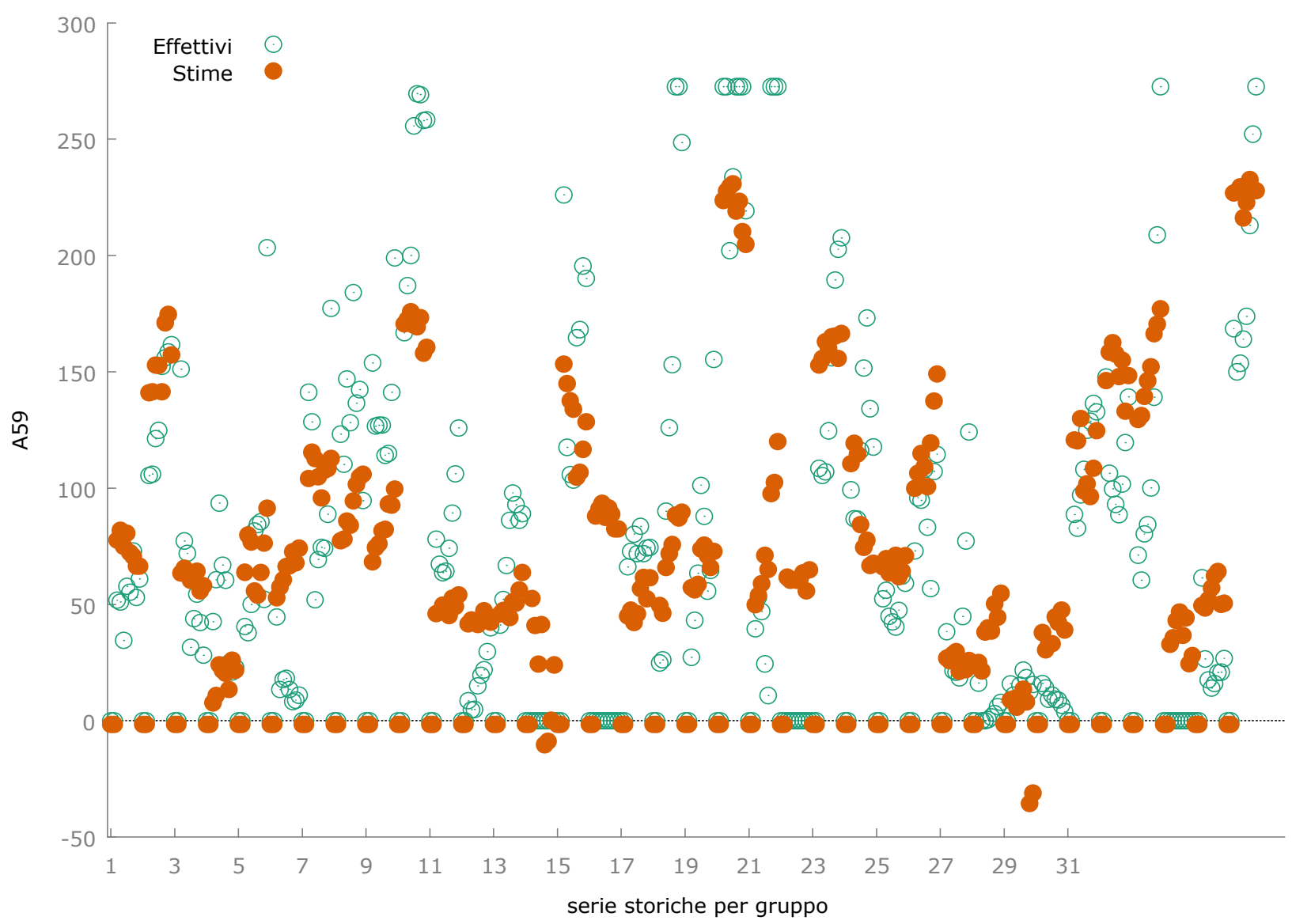

Effetti fissi, usando 360 osservazioni

Incluse 36 unità cross section

Lunghezza serie storiche $=10$

Variabile dipendente: A59

\begin{tabular}{lccccc}
\hline & Coefficiente & Errore Std. & rapporto $t$ & $p$-value & \\
\hline \hline const & $-1,71181$ & 4,13336 & $-0,4141$ & 0,6790 & \\
\hline A19 & 0,434459 & 0,0589763 & 7,367 & $<0,0001$ & $* * *$ \\
\hline A22 & $-1,91873$ & 0,345522 & $-5,553$ & $<0,0001$ & $* * *$ \\
\hline A24 & 1,64568 & 0,216642 & 7,596 & $<0,0001$ & $* * *$ \\
\hline A28 & $-0,487285$ & 0,117971 & $-4,131$ & $<0,0001$ & $* * *$ \\
\hline A35 & $-0,299902$ & 0,114325 & $-2,623$ & 0,0091 & $* * *$ \\
\hline A45 & $-0,404364$ & 0,0701948 & $-5,761$ & $<0,0001$ & $* * *$ \\
\hline
\end{tabular}

Media var. dipendente

68,38460

SQM var. dipendente

75,57819

Somma quadr. residui 421032,5

E.S. della regressione

36,38683

R-quadro LSDV

$0,794681 \quad$ R-quadro intra-gruppi

0,604278 


\begin{tabular}{lrlr}
\hline LSDV F(41, 318) & 30,01982 & P-value(F) & $2,90 \mathrm{e}-86$ \\
\hline Log-verosimiglianza & $-1782,403$ & Criterio di Akaike & 3648,806 \\
\hline Criterio di Schwarz & 3812,022 & Hannan-Quinn & 3713,704 \\
\hline rho & 0,636696 & Durbin-Watson & 0,698379 \\
\hline
\end{tabular}

Test congiunto sui regressori -

Statistica test: $\mathrm{F}(6,318)=80,9325$

con p-value $=\mathrm{P}(\mathrm{F}(6,318)>80,9325)=4,5806 \mathrm{e}-061$

Test per la differenza delle intercette di gruppo -

Ipotesi nulla: i gruppi hanno un'intercetta comune

Statistica test: $\mathrm{F}(35,318)=6,6554$

con $\mathrm{p}$-value $=\mathrm{P}(\mathrm{F}(35,318)>6,6554)=5,22738 \mathrm{e}-022$

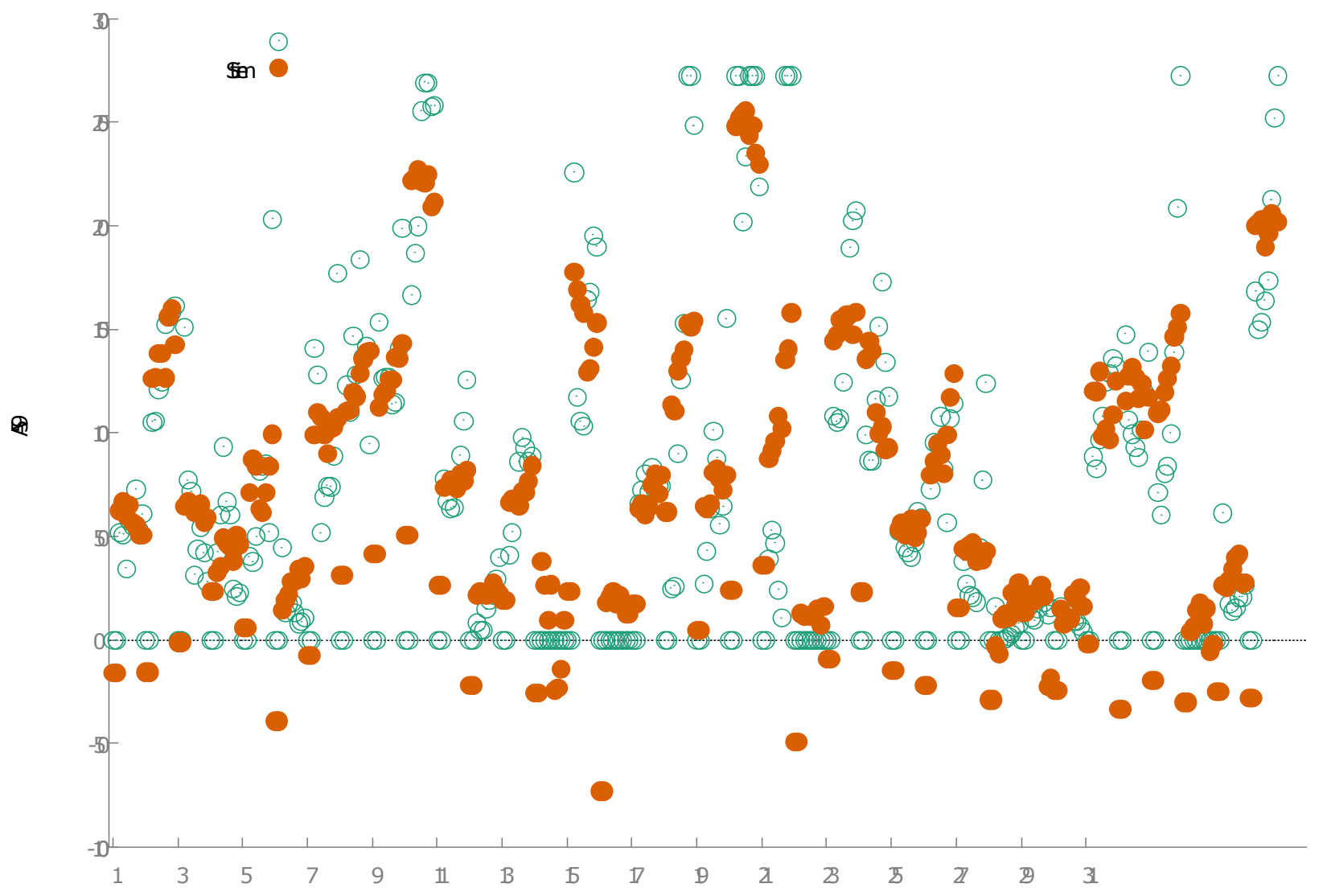

Modello 59: WLS, usando 360 osservazioni

Incluse 36 unità cross section 
Variabile dipendente: A59

\begin{tabular}{|c|c|c|c|c|c|}
\hline \multicolumn{6}{|c|}{ Variabile dipendente: A59 } \\
\hline \multicolumn{6}{|c|}{ Pesi basati sulle varianze degli errori per unità } \\
\hline \multicolumn{2}{|c|}{ Coefficiente } & Errore Std. & rapporto $t$ & \multicolumn{2}{|l|}{ p-value } \\
\hline const & $-2,83458$ & 3,30222 & $-0,8584$ & \multicolumn{2}{|l|}{0,3913} \\
\hline A19 & 0,442011 & 0,0312081 & 14,16 & $<0,0001$ & $* * *$ \\
\hline A22 & $-1,50959$ & 0,160217 & $-9,422$ & $<0,0001$ & $* * *$ \\
\hline $\mathrm{A} 24$ & 1,24220 & 0,106511 & 11,66 & $<0,0001$ & $* * *$ \\
\hline $\mathrm{A} 28$ & $-0,328202$ & 0,0490830 & $-6,687$ & $<0,0001$ & $* * *$ \\
\hline A 35 & $-0,150725$ & 0,0465266 & $-3,240$ & 0,0013 & $* * *$ \\
\hline A45 & $-0,346997$ & 0,0330522 & $-10,50$ & $<0,0001$ & $* * *$ \\
\hline \multicolumn{6}{|c|}{ Statistiche basate sui dati ponderati: } \\
\hline Somma quadr. residui & \multicolumn{2}{|c|}{341,0139} & E.S. della regressione & \multicolumn{2}{|c|}{0,982876} \\
\hline R-quadro & \multicolumn{2}{|c|}{0,738162} & R-quadro corretto & \multicolumn{2}{|c|}{0,733712} \\
\hline $\mathrm{F}(6,353)$ & \multicolumn{2}{|c|}{165,8605} & P-value $(F)$ & \multicolumn{2}{|c|}{$1,66 \mathrm{e}-99$} \\
\hline Log-verosimiglianza & \multicolumn{2}{|c|}{$-501,0653$} & Criterio di Akaike & \multicolumn{2}{|c|}{1016,131} \\
\hline Criterio di Schwarz & \multicolumn{2}{|c|}{1043,333} & Hannan-Quinn & \multicolumn{2}{|c|}{1026,947} \\
\hline & Statistiche & basate sui da & originali: & & \\
\hline Media var. dipendente & 68,3 & 460 & var. dipendente & & 57819 \\
\hline Somma quadr. residui & 749 & 35,0 & ella regressione & & 8881 \\
\hline
\end{tabular}




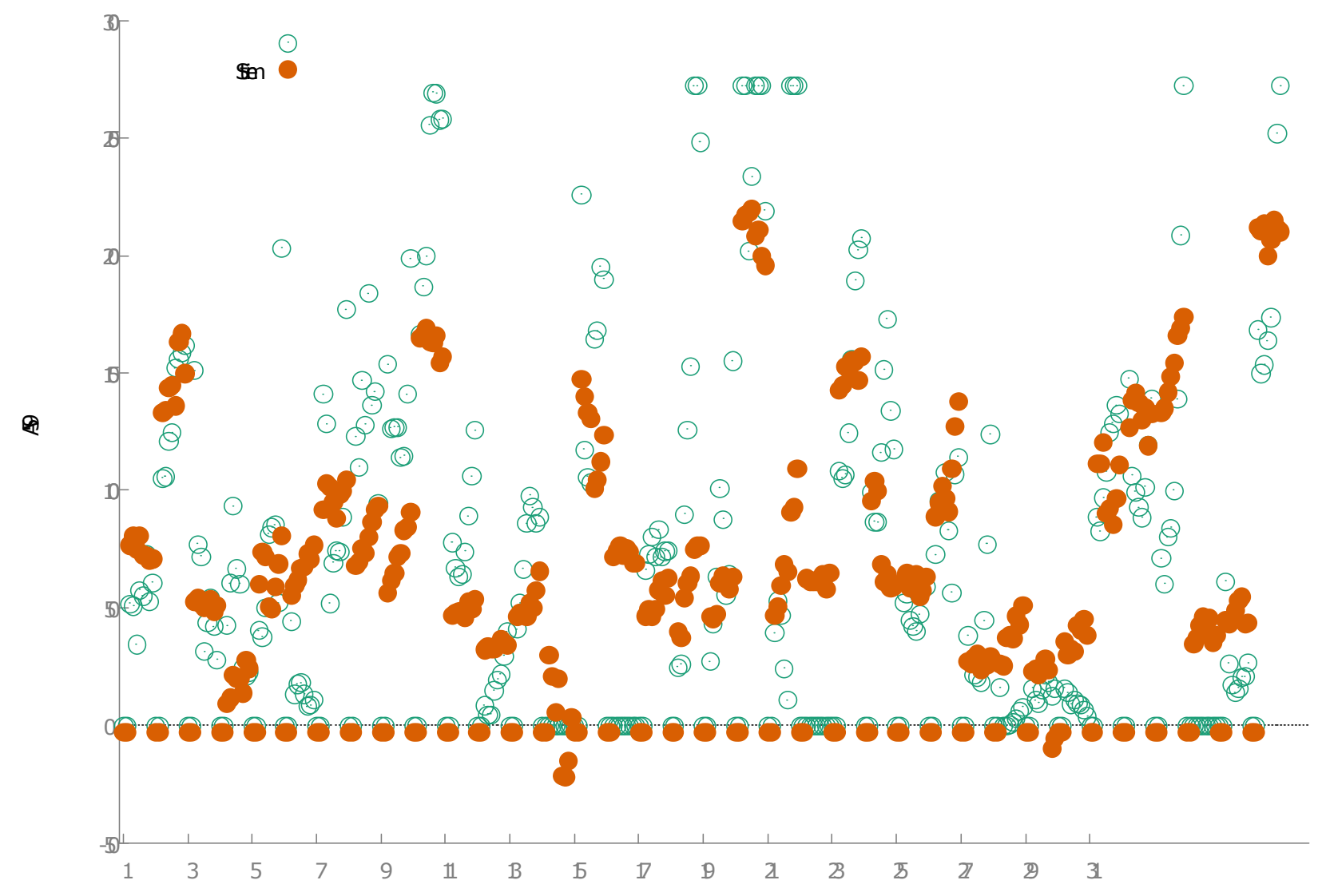

\begin{tabular}{|c|}
\hline Modello 58: Pooled OLS, usando 360 osservazioni \\
\hline Incluse 36 unità cross section \\
\hline Lunghezza serie storiche $=10$ \\
\hline Variabile dipendente: A59 \\
\hline
\end{tabular}

\begin{tabular}{lccccc}
\hline & Coefficiente & Errore Std. & rapporto $t$ & $p$-value & \\
\hline const & $-1,21441$ & 4,75104 & $-0,2556$ & 0,7984 & \\
\hline A19 & 0,448861 & 0,0374034 & 12,00 & $<0,0001$ & $* * *$ \\
\hline A22 & $-1,92372$ & 0,233785 & $-8,229$ & $<0,0001$ & $* * *$ \\
\hline A24 & 1,54652 & 0,151529 & 10,21 & $<0,0001$ & $* * *$ \\
\hline A28 & $-0,441353$ & 0,0796777 & $-5,539$ & $<0,0001$ & $* * *$ \\
\hline A35 & $-0,268766$ & 0,0714984 & $-3,759$ & 0,0002 & $* * *$ \\
\hline A45 & $-0,394264$ & 0,0442359 & $-8,913$ & $<0,0001$ & $* * *$ \\
\hline
\end{tabular}

\begin{tabular}{lrlr}
\hline Media var. dipendente & 68,38460 & SQM var. dipendente & 75,57819 \\
\hline Somma quadr. residui & 729444,0 & E.S. della regressione & 45,45782 \\
\hline R-quadro & 0,644283 & R-quadro corretto & 0,638237 \\
\hline F(6, 353) & 106,5603 & P-value(F) & $3,90 \mathrm{e}-76$ \\
\hline Log-verosimiglianza & $-1881,326$ & Criterio di Akaike & 3776,652 \\
\hline
\end{tabular}




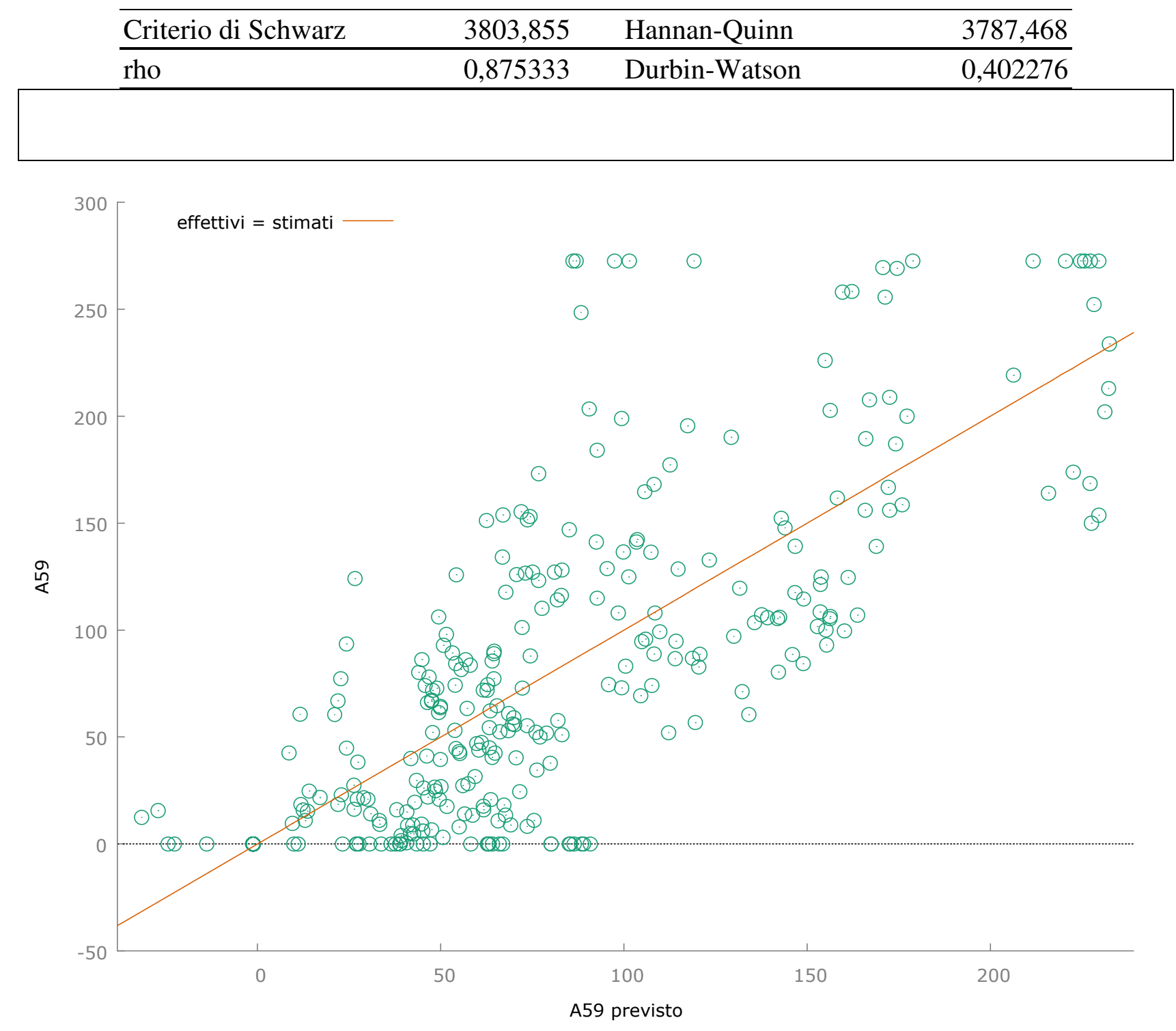

\begin{tabular}{|c|c|c|c|c|c|}
\hline \multicolumn{6}{|c|}{ Modello 57: Panel dinamico a un passo, usando 288 osservazioni } \\
\hline \multicolumn{6}{|c|}{ Incluse 36 unità cross section } \\
\hline \multicolumn{6}{|c|}{ Matrice $\mathrm{H}$ conforme ad Ox/DPD } \\
\hline \multicolumn{6}{|c|}{ Variabile dipendente: A59 } \\
\hline & Coefficiente & Errore Std. & $z$ & p-value & \\
\hline A59(-1) & $-0,248649$ & 0,147827 & $-1,682$ & 0,0926 & * \\
\hline const & 8,86477 & 2,66323 & 3,329 & 0,0009 & $* * *$ \\
\hline A19 & 0,360208 & 0,0923127 & 3,902 & $<0,0001$ & $* * *$ \\
\hline A22 & $-2,11160$ & 0,537316 & $-3,930$ & $<0,0001$ & $* * *$ \\
\hline A24 & 1,42184 & 0,376609 & 3,775 & 0,0002 & $* * *$ \\
\hline A28 & $-0,325622$ & 0,161091 & $-2,021$ & 0,0432 & $* *$ \\
\hline A35 & $-0,517182$ & 0,217259 & $-2,380$ & 0,0173 & $* *$ \\
\hline A45 & $-0,295887$ & 0,0991691 & $-2,984$ & 0,0028 & $* * *$ \\
\hline
\end{tabular}




\begin{tabular}{|c|}
\hline Somma quadr. residui $282954,2 \quad$ E.S. della regressione \\
\hline Numero di strumenti $=28$ \\
\hline Test per errori AR(1): $\mathrm{z}=0,99328[0,3206]$ \\
\hline Test per errori AR(2): $\mathrm{z}=-1,28794[0,1978]$ \\
\hline Test di sovra-identificazione di Sargan: Chi-quadro(20) $=49,7443[0,0002]$ \\
\hline Test (congiunto) di Wald: Chi-quadro(7) $=153,719[0,0000]$ \\
\hline \\
\hline
\end{tabular}

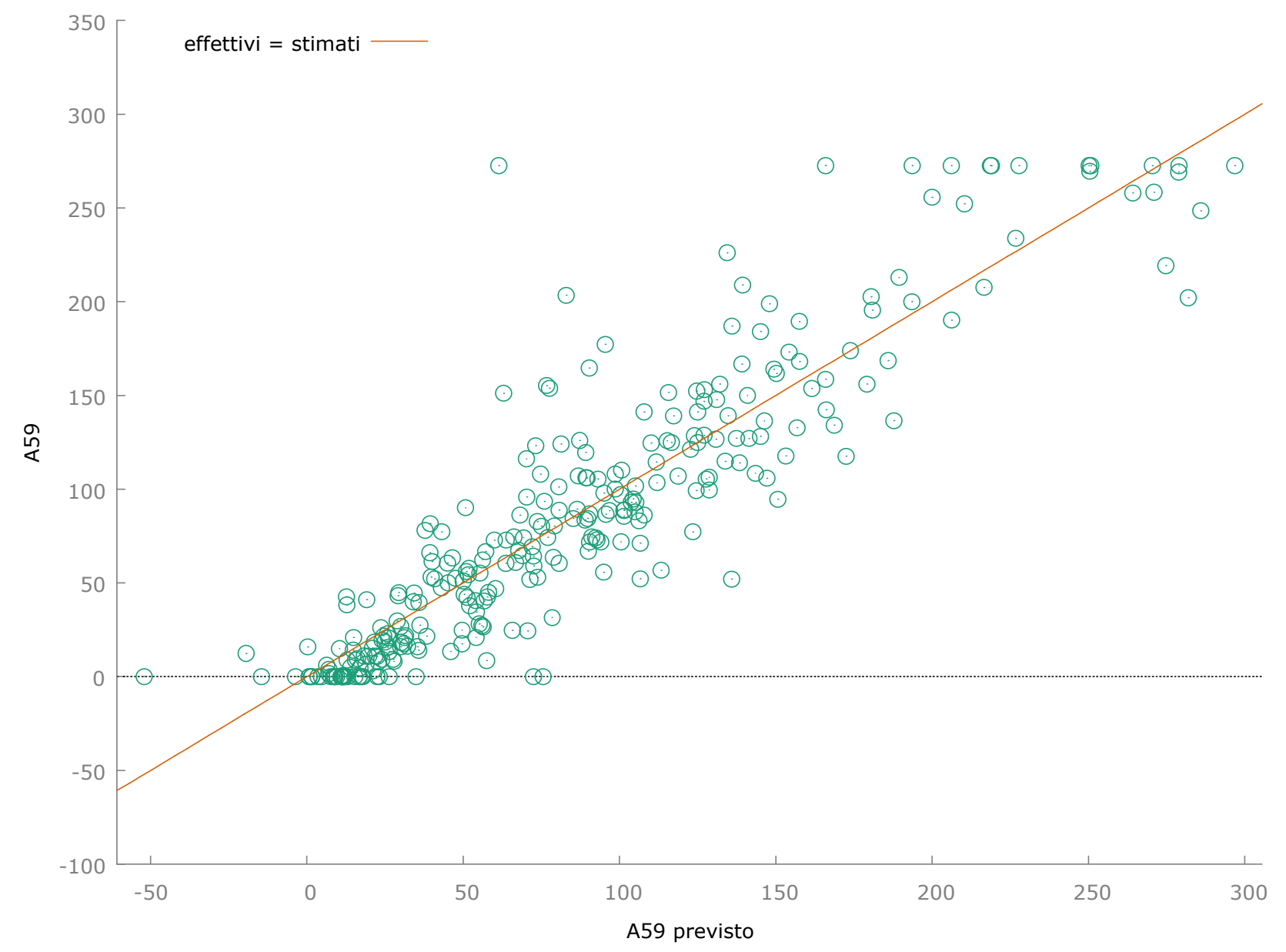

\subsection{Clusterization with k-Means}




\begin{tabular}{|c|c|c|c|c|c|}
\hline & 20 & & Countries & Cluster & Silhouette \\
\hline 1 & 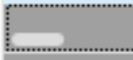 & 58.6266 & Austria & $\mathrm{C} 1$ & 0.629212 \\
\hline 3 & 0 & 21.3567 & Bulgaria & $\mathrm{C} 1$ & 0.623759 \\
\hline 14 & 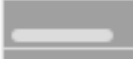 & 121.914 & Croatia & $\mathrm{C} 1$ & 0.588289 \\
\hline 6 & 0 & 37.5492 & Czechia & $\mathrm{C} 1$ & 0.700122 \\
\hline 10 & D & 48.8906 & Greece & $\mathrm{C} 1$ & 0.695353 \\
\hline 24 & $\infty$ & 61.9455 & Poland & C1 & 0.649205 \\
\hline 26 & 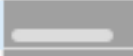 & 122.035 & Romania & $\mathrm{C} 1$ & 0.630038 \\
\hline 27 & - & 11.69 & Serbia & $\mathrm{C} 1$ & 0.691003 \\
\hline 30 & 0 & 25.0394 & Slovakia & $\mathrm{Cl}$ & 0.700366 \\
\hline 29 & & 7.48219 & Slovenia & $\mathrm{C} 1$ & 0.698102 \\
\hline 31 & 0 & 41.2647 & Ukraine & $\mathrm{C} 1$ & 0.700439 \\
\hline 2 & & 194.025 & Belgium & $\mathrm{C} 2$ & 0.648336 \\
\hline 5 & & 304.065 & Cyprus & $\mathrm{C} 2$ & 0.568723 \\
\hline 8 & & 212.122 & Denmark & $\mathrm{C} 2$ & 0.587588 \\
\hline 9 & & 253.895 & Estonia & $\mathrm{C} 2$ & 0.633624 \\
\hline 12 & & 304.065 & Finland & $\mathrm{C} 2$ & 0.651303 \\
\hline 7 & & 136.424 & Germany & $\mathrm{C} 2$ & 0.563887 \\
\hline 15 & 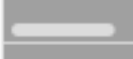 & 124.254 & Hungary & $\mathrm{C} 2$ & 0.555966 \\
\hline 16 & & 203.655 & Ireland & $\mathrm{C} 2$ & 0.61683 \\
\hline 17 & 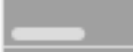 & 85.6627 & Italy & $\mathrm{C} 2$ & 0.518113 \\
\hline 18 & & 165.112 & Lithuania & $\mathrm{C} 2$ & 0.556738 \\
\hline 22 & & 231.243 & Netherlands & $\mathrm{C} 2$ & 0.583754 \\
\hline 23 & 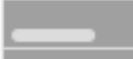 & 99.0682 & Norway & $\mathrm{C} 2$ & 0.649441 \\
\hline 25 & $\longrightarrow$ & 124.069 & Portugal & $\mathrm{C} 2$ & 0.620526 \\
\hline 11 & & 172.509 & Spain & $\mathrm{C} 2$ & 0.664799 \\
\hline 28 & & 219.863 & Sweden & $\mathrm{C} 2$ & 0.650471 \\
\hline 4 & & 269.751 & Switzerland & $\mathrm{C} 2$ & 0.553598 \\
\hline 20 & 으 & 22.7196 & Latvia & $\mathrm{C} 3$ & 0.544285 \\
\hline 21 &. & $\begin{array}{l}7.87253 \\
70.707\end{array}$ & Malta & $\mathrm{C} 3$ & 0.592851 \\
\hline 13 & & 292.787 & France & $\mathrm{C} 4$ & 0.664752 \\
\hline 19 & & 304.065 & Luxembourg & $\mathrm{C4}$ & 0.658654 \\
\hline 32 & & 304.065 & United Kingdom & $\mathrm{C} 4$ & 0.530179 \\
\hline
\end{tabular}




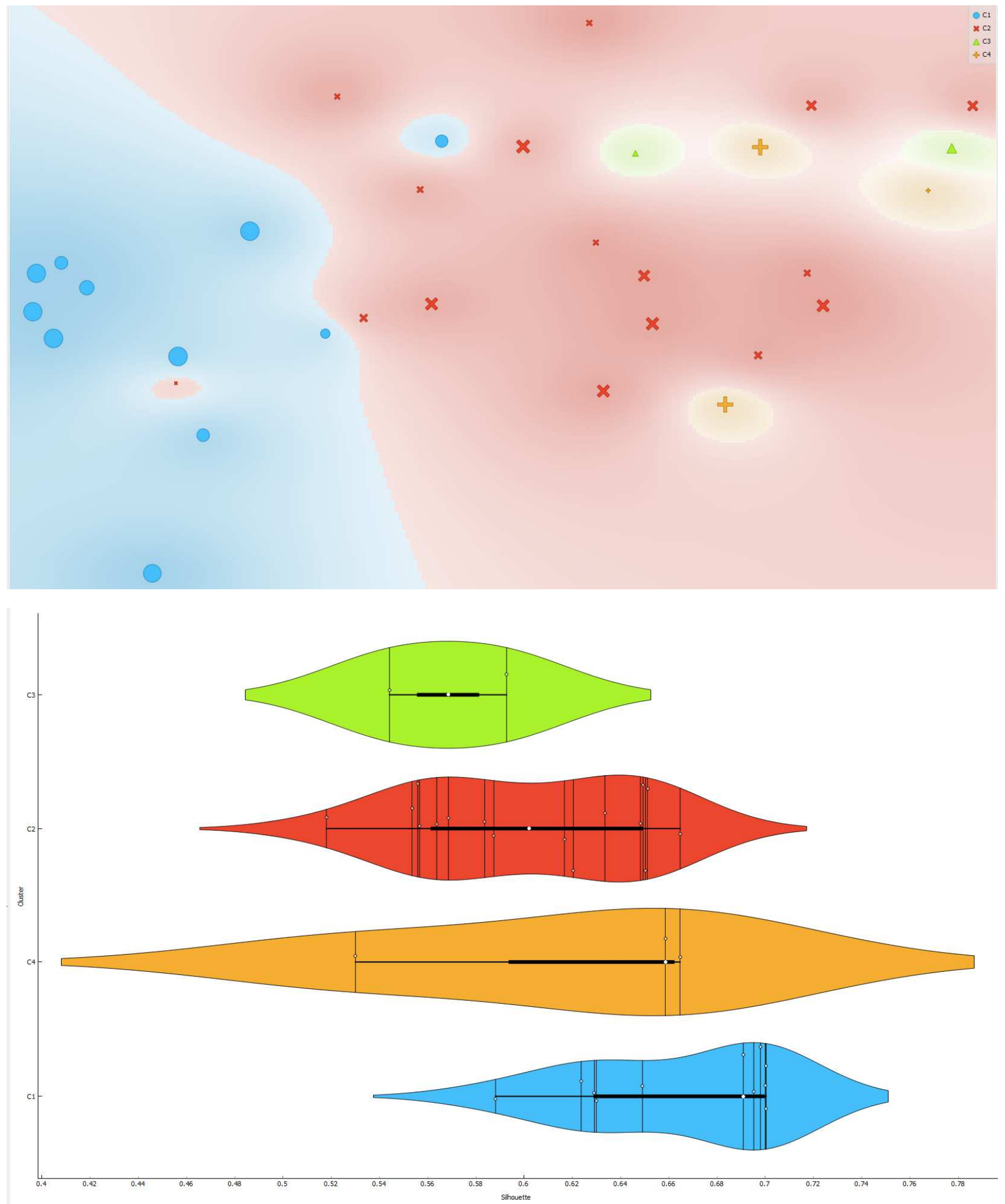




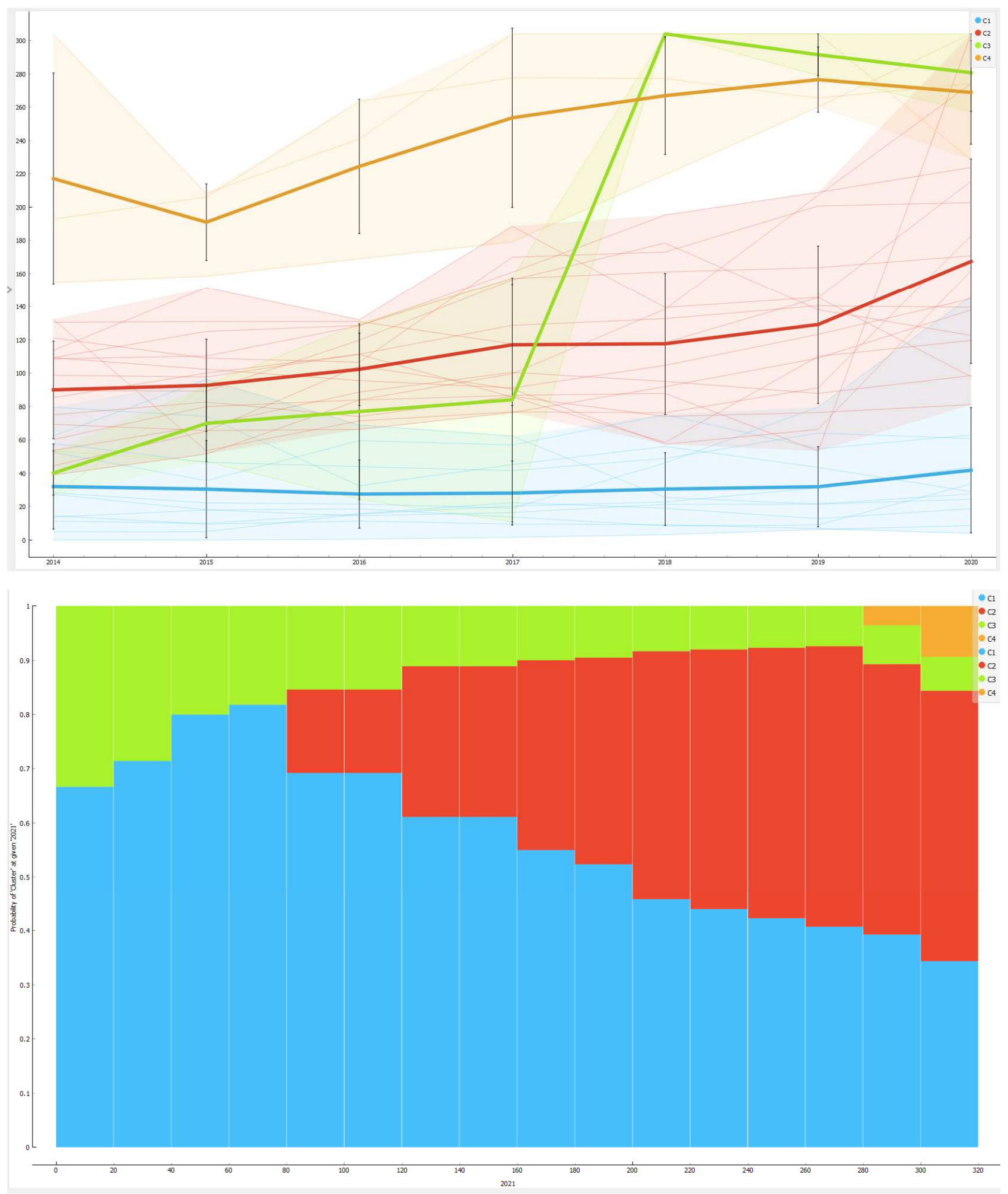




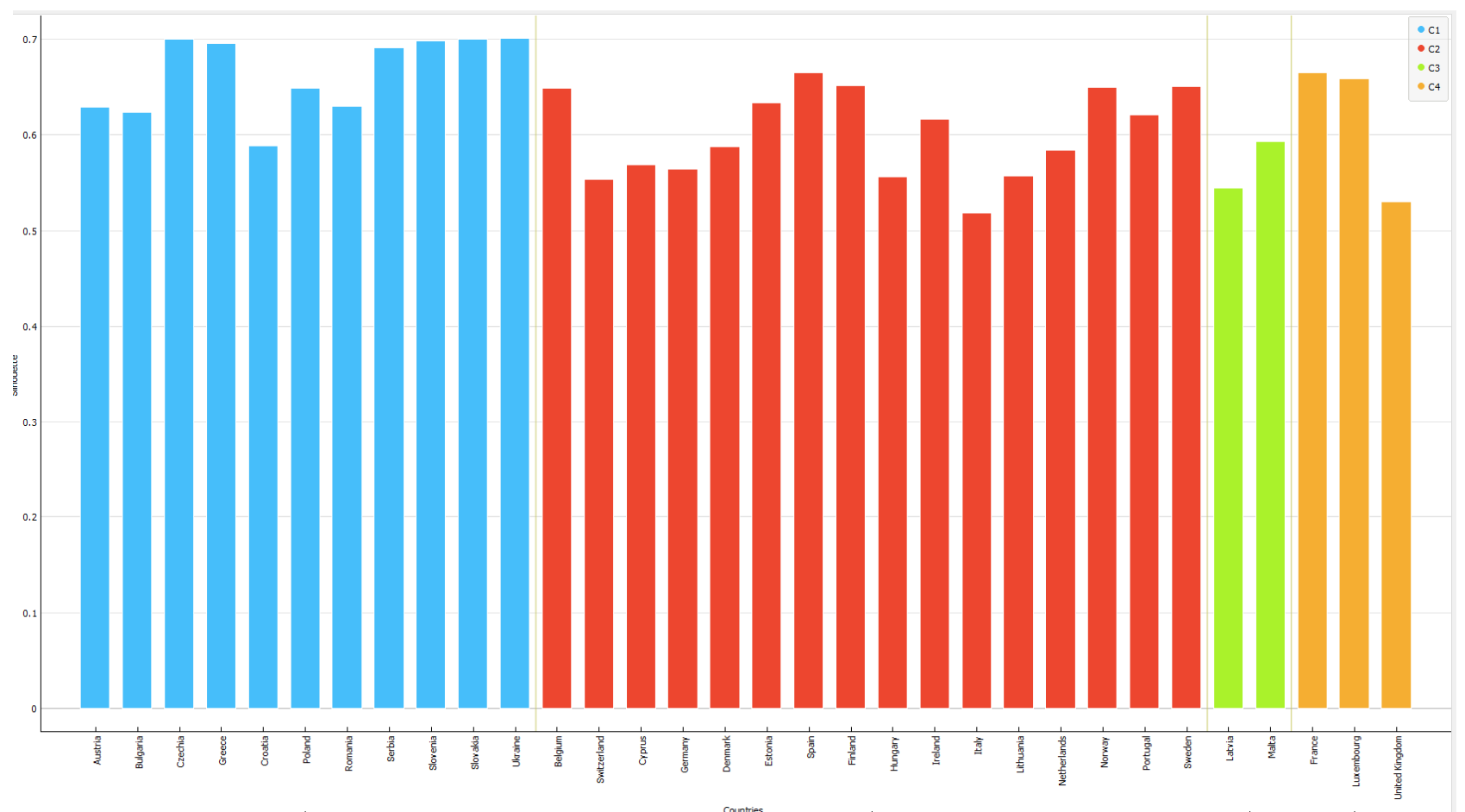

Cluster

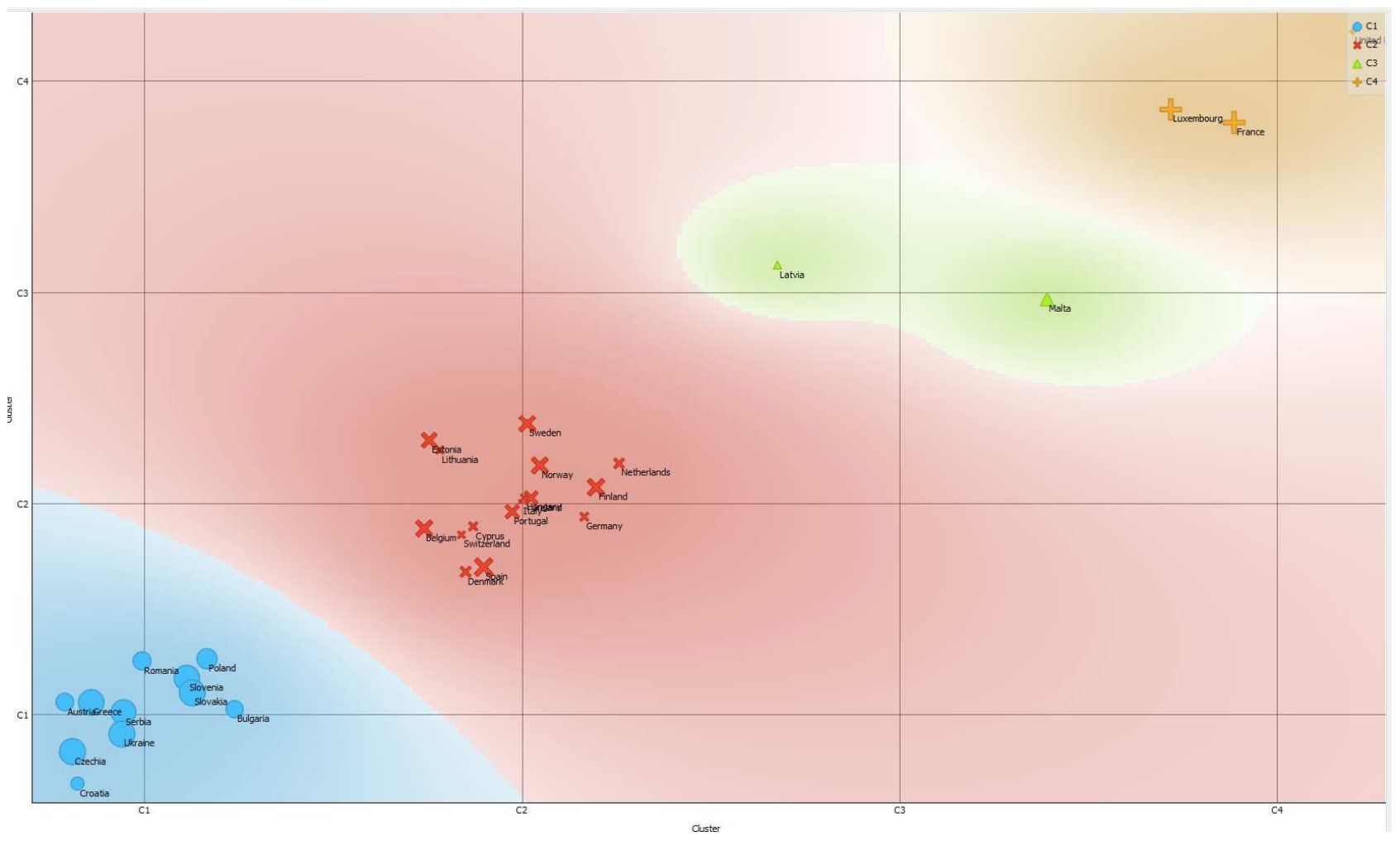

6.3 Machine Learning and Predictions Outputs

RProp MLP Learner

Normalizer

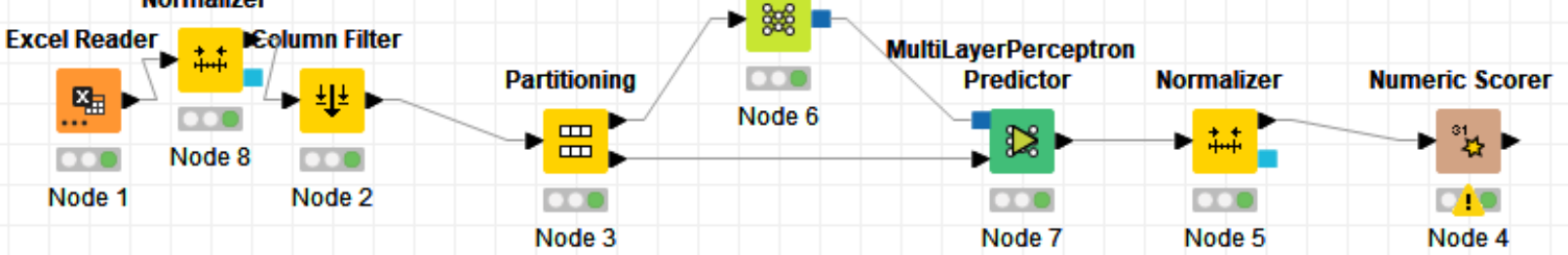



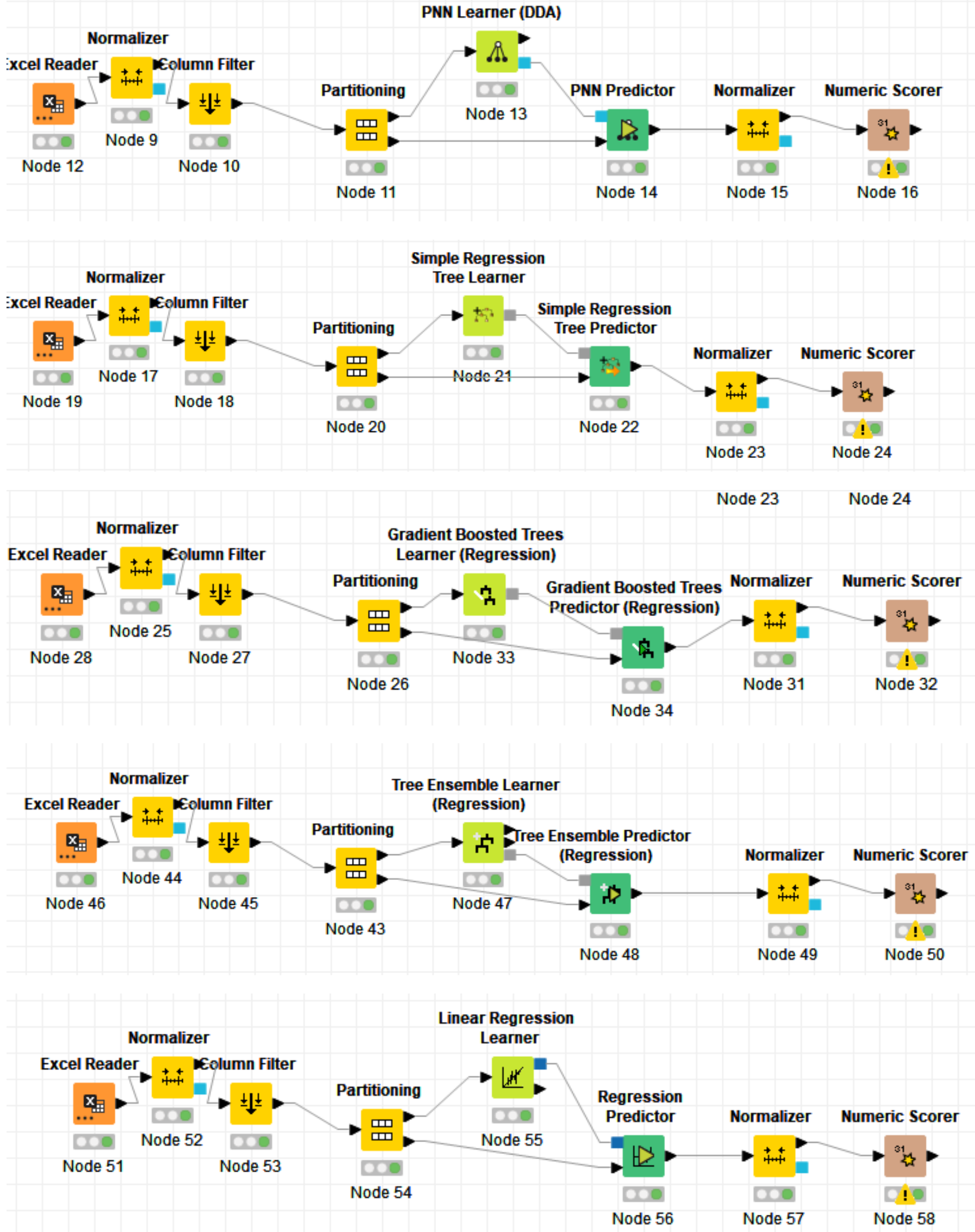
Normalizer

Excel Reader $+\ldots$ Column Filter

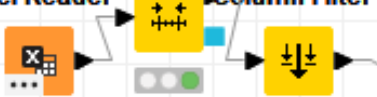

Node 60

Node 59
Polynomial

Regression Learner

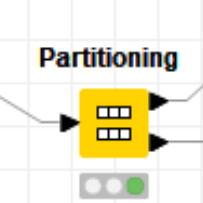

Node 62 $\rightarrow$ 訨 Regression

Predictor

Node 63
Predicto

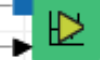

(cose

Node 64
Normalizer Numeric Scorer

!

Node 66

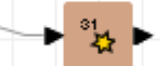

